\title{
Aumento de capital sin derecho de suscripción preferente y el caso específico de las sociedades con distintas clases de acciones. UN ANÁLISIS AL ARTÍCULO 259 DE LA LEY GENERAL DE SOCIEDADES
}

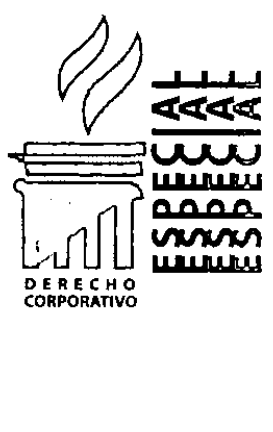

\section{Rafael Picasso Salinas}

Abogado por la Pontificia Universidad Católica del Perú. Profesor del curso Seminario de Mercado de Valores en la Universidad de Lima y del curso de Mercado de Valores en la Pontificia Universidad Católica del Perú.

Victor H. Lazo Vasquez

Abogado por la Universidad de Lima.

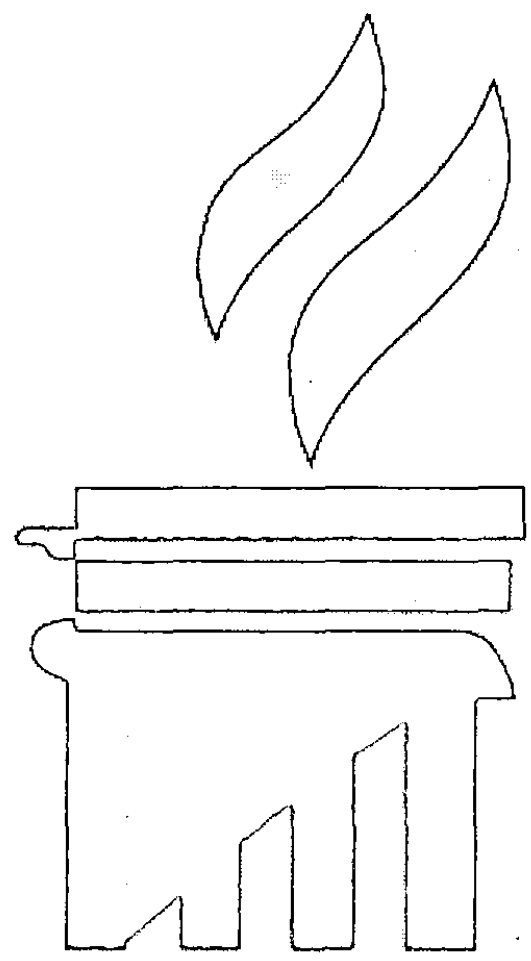

SUMARI0:

I. Preámbulo.

II. El artículo 259 de la LGS:

1. DSP;

2. La diferencia entre la exclusión absoluta y la exclusión relativa en materia de DSP;

3. Antecedentes del articulo 259 de la LGS;

4. Justificación de la exclusión de la DSP.

III. Requisitos del artículo 259 de la LGS:

1. Explicación en la junta general de accionistas para su uso;

2. El caso de la oferta pública.

IV. El caso especifico de las sociedades con distintas clases de acciones:

1. Las juntas especiales y las circunstancias que las generan;

2. La afectación a los derechos de los accionistas sin derecho a voto como consecuencia de la supresión al DSP:

2.1. ¿Requiere la aplicación del artículo 259 de la LGS de una junta especial previa?

v. Conclusiones. 


\section{PREÁMBULO}

El artículo 259 de la Ley General de Sociedades (en adelante, la "LGS") establece que en los casos de las sociedades anónimas abiertas se puede efectuar un aumento de capital sin observar el derecho de suscripción preferente (en adelante, el "DSP"). El presente artículo tiene como finalidad sustentar las razones por la cual la LGS contiene dicho articulo, explicando las circunstancias que generaron su existencia, asi como los requisitos y parámetros que lo rodean.

Asimismo, parte de este análisis se centrará en determinar si el mencionado artículo 259 viola algún tipo de derecho, deteniéndonos en el caso específico de aquellos accionistas que tienen acciones que no cuentan con derecho a voto.

\section{EL ARTÍCULO 259 DE LA LGS}

Como primer punto, empezaremos explicando en qué consiste el artículo 259 de la LGS y cuáles son las razones que sustentan su utilidad. $A$ efectos del análisis a efectuar, citamos el artículo en cuestión:

\section{"Artículo 259.-Aumento de capital sin derecho preferente:}

En el aumento de capital por nuevos aportes a la sociedad anónima abierta se podrá establecer que los accionistas no tienen derecho preferente para suscribir las acciones que se creen siempre que se cumplan los siguientes requisitos:

1. Que el acuerdo haya sido adoptado en la forma y con el quórum que corresponda, conforme a lo establecido en el articulo 257 y que además cuente con el voto de no menos del cuarenta por ciento de las acciones suscritas con derecho de voto; $y$,

2. Que el aumento no esté destinado, directa o indirectamente, a mejorar la posición accionaria de alguno de los accionistas.
Excepcionalmente, sepodrá adoptar el acuerdo con un número de votos menor al indicado en el inciso 1 anterior, siempre que las acciones a crearse vayan a ser objeto de oferta pública."

Como podemos ver, el artículo 259 de la LGS - ubicado dentro del articulado de sociedades anónimas abiertas- establece la posibilidad de efectuar aumentos de capital excluyendo el DSP de los accionistas, siendo menester el cumplir con dos requisitos esenciales, señalados en el texto del propio artículo.

Como sabemos, las sociedades anónimas abiertas son aquellas sociedades que por su propia naturaleza y por la finalidad para la cual son constituidas cuentan con un gran número de accionistas y tienen una serie de particularidades que las distinguen de otros tipos de sociedades; particularidades que cumplen la finalidad de facilitar su funcionamiento. Es realmente dentro de esta idea que se encuadra el artículo 259 de la LGS, bajo análisis.

\section{DSP}

El DSP es un derecho inherente y mínimo a la calidad de accionista, reconocido como uno de los pilares básicos de la regulación societaria. En palabras muy simples, el DSP es"(...) la potestad que la Ley atribuye a los socios en los aumentos de capital para suscribir acciones nuevas en cuantía proporcional a las acciones antiguas poseidas.".

En efecto, el DSP, lejos de ser un mero privilegio, es una forma de protección legal que impide que ante el acontecimiento de un aumento de capital se produzcan una de dos situaciones:

a) Que el accionista vea su porcentaje accionarial diluido como consecuencia del aumento de capital; y,

b) Que personas ajenas a los accionistas originales formen parte de la sociedad; situación que podría ser perjudicial para algunos accionistas o incluso, para la propia sociedad.

1 SÁNCHEZ ANDRÉS, Aníbal, El Derecho de Suscripción Preferente del accionista, Editorial Civitas, Madrid, 1990, p. 21. 
EI DSP impide que ocurran estas consecuencias perjudiciales, al darles a los accionistas la opción de pagar el aumento de capital en su integridad, impidiendo así su dilución o evitando que personas ajenas se conviertan en accionistas.

En este sentido, la importancia del DSP es tal, que este se encuentra contemplado no solo en los artículos 95,96 y 207 de la LGS sino que además, es reconocido tanto explícita como implícitamente a lo largo de la LGS, para todo tipo de sociedades. En este orden de ideas, el artículo 207 de la LGS establece que:

"Artículo 207.- Derecho de Suscripción Preferente:

En el aumento de capital por nuevos aportes, los accionistas tienen derecho preferencial para suscribir, a prorrata de su participación accionaria, las acciones que se creen. Este derecho es transferible en la forma establecida en la presente ley.

No pueden ejercer este derecho los accionistas que se encuentren en mora en el pago de los dividendos pasivos, y sus acciones no se computarán para establecer la prorrata de participación en el derecho de preferencia.

No existe derecho de suscripción preferente en el aumento de capital por conversión de obligaciones en acciones, en los casos de los artículos 103 y 259 ni en los casos de reorganización de sociedades establecidos en la presente ley."

Explicando las razones de existencia de dicho derecho, Garrigues y Uría ${ }^{3}$ nos comentan que:

"El fundamento de ese derecho está, de una parte, en que toda emisión de acciones nuevas en una sociedad próspera, con buenas reservas y perspectivas halagüeñas, reduce la proporción en que se encuentran las acciones viejas en el patrimonio social, e implica necesariamente la rebaja del valor de esas acciones en la medida en que las acciones nuevas van a absorber una parte de las reservas y de las expectativas de futuros beneficios. (...) Pero, aparte de esto, hay otra razón igualmente poderosa para el reconocimiento legal de ese derecho: la necesidad. de mantener el statuo quo de derechos conseguido (sic) por los socios con la tenencia de un determinado número de acciones.

(...)

Del art. 39, núm. 3, se infiere claramente que es uno de los cuatro derechos que constituyen el contenido minimo y esencial de toda acción"

Así pues, conforme nos lo explica Echaiz Moreno ${ }^{4}$ :

"El ordenamiento jurídico peruano en miateria societaria considera que el Derecho de Suscripción Preferente integra el abanico de derechos mínimos del socio, tanto asi que se lo reconoce independientemente que el socio sea titular de acciones con derecho a voto o sin derecho a él".

Sin embargo, no obstante ser un derecho básico y esencial, el artículo 259 de la propia LGS permite que este derecho sea excluido -en casos particulares y cumpliendo una serie de requisitos-por la junta general de accionistas de una sociedad anónima abierta. Punto importante a tener en cuenta es que esta exclusión no opera a un nivel permanente, ni tampoco en todos los casos de aumento de capital en las sociedades anónimas abiertas sino que tiene ciertas condiciones y requisitos. En este orden de ideas, los

2 Referidos a los derechos de los accionistas con derecho a voto; accionistas sin derecho a voto; y, al derecho de suscripción preferente, respectivamente.

3 GARRIGUES, Joaquín y URIA, Rodrigo, Comentario a la Ley de Sociedades Anónimas, Tomo I, Madrid, Instituto de Estudios Políticos, año 1952, pp. 405-406.

4 ECHAIZ MORENO, Daniel, EI Derecho de Suscripción Preferente. En: Actualidad Jurídica, No. 150, Año 2006, p. 276. 
accionistas de las sociedades anónimas abiertas, al igual que cualquier otro accionista en otro tipo de sociedad cuentan con un DSP desde el momento en que adquieren la calidad de accionista (o socio, de ser el caso).

Esta exclusión momentánea del DSP, sin embargo, no infringe ni viola ningún otro derecho de los accionistas, ya que -como veremos más adelante- las particulares condiciones y características de la sociedad anónima abierta lo hacen perfectamente lícito e inclusive, necesario.

\section{La diferencia entre la exclusión absoluta y la exclusión relativa en materia de DSP}

Debemos empezar explicando que en materia de exclusión del DSP se puede distinguir entre dos clases: la exclusión absoluta y la exclusión relativa. De acuerdo a Rodrigo Prado, siguiendo a Vásquez Albert ${ }^{5}$, la diferencia radica en que en la supresión o exclusión absoluta se elimina el DSP de manera total y para la generalidad de aumentos de capital que una sociedad determinada pueda tener. Aunque en nuestra opinión, una exclusión absoluta nunca podría suceder (por ser el artículo 207 de la LGS una norma imperativa y no permitir el pacto en contrario) si sería posible que un grupo de accionistas celebren un convenio en el que establezcan que no ejercerán sus respectivos DSP, efectuando una suerte de prohibición general aplicable a los accionistas que lo celebren. ${ }^{6}$

De manera contraria, tenemos la exclusión relativa, en la que se restringe el DSP de los accionistas para casos concretos. Como ya se ha explicado de manera detallada, nuestra LGS ha adoptado la exclusión relativa, permitiendo para el caso especifico de las sociedades anónimas abiertas y previo acuerdo de junta, eliminar el DSP para cada aumento de capital en concreto.?

\section{Antecedentes del artículo 259 de la LGS}

El antecedente inmediato del artículo 259 de la LGS lo encontramos en el último párrafo del artículo 6 del ya derogado Decreto Legislativo 672 , el cual a la letra decía que:

\begin{abstract}
"La Sociedad puede aprobar la emisión de una o más series especiales de acciones, sin derecho de preferencia de los socios, siempre y cuando el acuerdo sea adoptado con el voto favorable de acciones representativas de más del veinte porciento (20\%) del capital social pagado. Sin perjuicio de lo expuesto en el párrafo anterior la eficacia del acuerdo adoptado está sujeta a su aprobación por CONASEV, debiendo acreditar la Sociedad, para este efecto, de forma razonable, que la emisión no se destinará directa ni indirectamente a mejorar la posición accionaria de alguno de los socios de la Sociedad". (El subrayado es nuestro)
\end{abstract}

Este dispositivo permitía emitir una o mas series especiales de acciones sin respetar el DSP de los accionistas, utilizando un tenor muy similar al artículo bajo comentario de la actual LGS. En este orden de ideas, el mencionado decreto legislativo permitía la exclusión del DSP, exclu-

5 VÁSQUEZ ALBERT, Daniel, La Exclusión del Derecho de Suscripción Preferente, Editorial Civitas S.A., Madrid, 2000 , p. 74. Citado por RODRIGO PRADO, Lis Carlos, Op. Cit., p. 804.

6 No obstante, aclaramos que esto no implica de ninguna manera que los accionistas pierdan su DSP ya que, en esencia, siempre lo tendrán, al ser el mismo, un derecho básico e inherente de cada accionista. En este orden de ideas, en virtud del convenio, los accionistas podrian optar por renunciar al referido DSP en cada oportunidad que lo puedan ejercer; empero, de darse el caso que un accionista decida ejercer su DSP, podría hacerlo ya que, como dijimos, dicho accionista nunca habría perdido este derecho. Esta interpretación viene dada porque el artículo 207 de la LGS es realmente una norma imperativa, por lo que en virtud de la interpretación del artículo 8 de la LGS, si un convenio se opone a una norma de carácter imperativo, deberá prevalecer esta última.

7 Asimismo, el propio articulo 207 de la LGS establece otras excepciones, además del referido articulo 207, tales como el artículo 103 de la LGS y las reorganizaciones de sociedades, vale decir, la fusión, la escisión y la reorganización simple. Estas otras excepciones sin embargo, no serán objeto de análisis del presente artículo, por lo que nos enfocaremos únicamente en la excepción del artículo 259 de la LGS. 
sión que como hemos dicho, pertenecía en ese momento (y sigue perteneciendo) al ámbito de las sociedades anónimas abiertas.

En efecto, el referido Decreto Legislativo 672 establecía normas complementarias a las establecidas por la LGS, con la finalidad de regular algunos aspectos del funcionamiento de las sociedades anónimas. En otras palabras, la razón por la que salió esta norma es que la antigua LGS no contenía una disposición similar a esta, originándose justamente toda una serie de problemas al momento de efectuar un aumento de capital en aquellas sociedades con accionariado difundido; problemas que analizaremos más adelante.

\section{Justificación de la exclusión del DSP}

Como ya hemos mencionado, el artículo 259 de la LGS se encuentra dentro de la normativa especial relativa a las sociedades anónimas abiertas, tipo societario que se caracteriza principalmente por tener quórums y mayorías bajas y que podría, además, contar un amplio accionariado. ${ }^{8}$

A efectos de este artículo, analizaremos aquellas sociedades anónimas abiertas que cuentan efectivamente con un accionariado difundido. Esto, sin embargo, no enerva el hecho que todas las sociedades anónimas abiertas (sea que cuenten con un accionariado difundido o no) tienen la facultad de efectuar un aumento de capital excluyendo el DSP.

Pues bien, tal y como es usual en este tipo de sociedades, existe una gran cantidad de accionistas que son meramente especuladores o capitalistas, formando parte del accionariado de la sociedad meramente por intereses pecuniarios (retorno/rendimiento sobre la inversión efectuada) y no porque les interese realmente asumir la dirección o control de la sociedad. ${ }^{9}$

Así pues, tenemos que:

"La sociedad anónima contemporánea alberga marcadamente dos tipos de socios: por un lado, los socios mayoritarios, de mando o de controly, por otro lado, los socios minoritarios, especuladores o rentistas. Para los primeros el voto es imprescindible porque a través de él dominan la sociedad y conducen su destino, lo cual es irrelevante para los segundos en tanto saben que su reducida proporción en el capital social les impide ejercer una influencia dominante, situación que compensan con la rentabilidad obtenida por su inversión. Así, actualmente, las legislaciones societarias en el mundo permiten la coexistencia de acciones con derecho a voto y acciones sin derecho a él, a efectos de que los socios mayoritarios se interesen por las primeras, mientras que los socios minoritarios hagan lo propio con las segundas."10

Concordante con lo dicho, normalmente las sociedades que cuentan con este tipo de conformación accionaria, tienen dos tipos de acciones: con derecho a voto y sin derecho a voto. No obstante esto, todos los accionistas cuentan con ciertos derechos básicos que les corresponden, sin importar el tipo de acciones con las que cuentan; tales como el derecho a la información, solicitud de convocatoria a junta general de accionistas o el mencionado DSP.

8 Aunque esto no es necesariamente siempre así ya que, de conformidad con el artículo 249 de la LGS, una sociedad se puede constituir desde sus inicios como una sociedad anónima abierta, no habiendo ninguna limitación en torno al número mínimo de accionistas. Sin embargo, debemos puntualizar que el accionariado difundido es común entre las sociedades anónimas abiertas.

9 Aunque no es motivo de análisis, podemos mencionar brevemente que este tipo de sociedades tienen un amplio accionariado ya que requieren de grandes cantidades de capital, por lo que -usualmente- se abren a mercados financieros para captación masiva de fondos. Esto es necesario cuando la finalidad de la sociedad es perseguir un negocio grande o costoso. No obstante este beneficio, surgen pues ciertos problemas al momento de la dirección de la sociedad, no tanto por que todos los accionistas cuentan con derecho a voto (lo que sería por supuesto un inmenso problema) sino que existen ciertos derechos que requieren ser respetados y que hacen -a veces-que la toma de decisiones en las sociedades con accionariado difundido no sea tan veloz como a veces se quisiera.

10 ECHAIZ MORENO, Daniel, Op. Cit., p. 272. 
Retomando el caso específico de las sociedades anónimas abiertas, este tipo de sociedad debe adoptar ciertas decisiones necesarias para su funcionamiento y desarrollo; y, aún cuando esta decisión no sea adoptada por el 100\% de accionistas (por haber algunos que no cuentan con derecho a voto), ciertas decisiones tienen repercusiones en los derechos de todos los accionistas, indiferente de la clase o tipo de acciones con las que cuenten. Concordante con esto, hay decisiones que los accionistas que tienen el control pueden adoptar (accionistas que inclusive, podrían ser la minoría, si contáramos accionista por accionista), sin necesitar de respetar o cautelar los derechos del resto de los accionistas. ${ }^{11}$

En este orden de ideas, por ejemplo, una sociedad podría necesitar de un aumento de capítal; aumento de capital que aunque puede ser decidido por un número determinado de accionistas, conlleva una consecuencia que afecta a la totalidad de éstos: el derecho a suscribir preferentemente las acciones que se emitan como consecuencia del aumento de capital propuesto. ${ }^{12}$

Teniendo en cuenta esto, es perfectamente posible que el monto propuesto para el aumento no pueda ser asumido por todos; sea porque no tienen el dinero suficiente o porque, aún teniéndolo, no les interesa aportarlo (por estar en la sociedad únicamente por las utilidades que se puedan generar y no por un factor de control). En este orden de ideas, aquellos accionistas que no deseen aportar capital fresco a la sociedad tendrían que renunciar a su DSP, a efectos de facilitar el proceso de aumento de capital por ruedas, dándole la oportunidad a aquellos accionistas (o terceros) que sí desean aportar; haciendo todo el proceso más sencillo y rápido.

En un caso todavía más específico y que se centra aún más en la justificación del artículo objeto de análisis, tenemos el aumento de capital por aportes de personas que no son accionistas. En estos supuestos, se requiere que todos los actuales accionistas de la sociedad aprueben el ingreso de un nuevo accionista, renunciando a tales efectos a su DSP.

En estas situaciones, la sociedad tendría que consultar a todos y cada uno de los accionistas para que renuncien a su DSP o, en todo caso, convocarlos y reunirlos en junta general de accionistas para que todos renuncien al referido derecho. Considerando la alternativa de reunirlos, tenemos que decir que aún cuando asista la mayoría de los accionistas a la referida junta general de accionistas, seguirían con el problema que el $100 \%$ de los accionistas cuenta con su respectivo DSP y que el hecho que no hayan asistido a la junta general de accionistas no cambia en nada que dichos accionistas mantengan aún el derecho a suscribir preferentemente las acciones que se emitan.

En atención a lo expuesto, contar con el consentimiento de los accionistas resulta -en aquellas sociedades anónimas abiertas con accionariado difundido-extremadamente dificultoso, por no decir, inviable. Principalmente, porque no es fácil ubicar a todos y cada uno de los accionistas de la sociedad, pudiendo inclusive darse el caso que no se lleguen a ubicar nunca a algunos. En segundo lugar, si es que se llegaran a ubicar a todos, algunos podrían haber incluso fallecido, dejando atrás, posiblemente, el problema de efectuar una sucesión intestada. Nuevamente, reiteramos que pase lo que pase, todos y cada uno de los accionistas tienen DSP.

Debido a las complicaciones prácticas que esto conllevaria, así como el tiempo que esto demoraría, la LGS incluyó en su articulado la posibilidad de excluir el DSP para este tipo

11 Así por ejemplo, podemos mencionar a los cambios en ciertos artículos del estatuto (como la denominación social) o designación y remoción de apoderados y gerentes.

12 Hay que recordar que todos y cada uno de los accionistas cuentan con el DSP. En este sentido, concordamos con la opinión esgrimida por Echaíz Moreno cuando dice que: "Las normas resaltadas, estas son el articulo 95 inciso 4 literal a) y el artículo 96 inciso 5 literales a), b) y c) de la Ley General de Sociedades, consagran el Derecho de Suscripción Preferente tanto para los titulares de acciones con derecho a voto como sin derecho a él y tácitamente lo elevan a la categoría de derecho fundamental del socio al utilizar la expresión cuando menos" (ECHAIZ MORENO, Daniel, Op. Cit., p. 273). 
particular de sociedades anónimas, haciendo mucho más fácil y práctico llevar a cabo el acto del aumento de capital.

En este orden de ideas, Enrique Elías ${ }^{13}$ establece que:

"En razón a ello, los accionistas que efectivamente controlan la sociedad no tienen inconvenientes, en ciertos casos, en ver reducida su participación accionaria a cambio de capitales de terceros que impulsen las operaciones de la empresa.

Para que ello se pueda concretar, sin embargo, es imprescindible que la totalidad de los accionistas renuncien a su Derecho de Suscripción Preferente. Ahora bien, dada la gran cantidad de accionistas que tiene la S.A.A., esa circunstancia es un obstáculo para que la sociedad pueda conseguir aumentos de capital por parte de terceros.

Es por ello que la Ley General de Sociedades permite, a través del artículo 259, que la sociedad anónima abierta aumente su capital sin que sea necesaria la renuncia al Derecho de Suscripción Preferente que la ley otorga a sus accionistas (...)". (El subrayado es nuestro)

En opinión muy similar, aunque antes de la existencia del referido artículo 259 -o inclusive de la propia LGS bajo comentario- Julio Salas Sánchez ${ }^{14}$ opina lo siguiente:

"La idea básica que subyace en los regímenes legales que admiten la posibilidad de excluir el Derecho de Suscripción Preferente, es admitir el ingreso de nuevos accionistas que permita a la sociedad contar con determinados recursos que los socios no están en condiciones de aportar. No solo se trata de la cuantía de los recursos a aportar, sino también -en forma conjunta o separada- de la conveniencia del ingreso de determinadas personas como accionistas de la sociedad.
Consideramos que es necesario adoptar una posición más flexible y admitir la exclusión del Derecho de Suscripción Preferente con el previo cumplimiento de determinados requisitos y rodeándola de las garantías que impidan que la figura sea utilizada en perjuicio de unos accionistas y en beneficios de otros (...)". (EI paréntesis y el subrayado son nuestros).

En este orden de ideas, y de lo visto hasta acá podemos afirmar lo siguiente:

1) La finalidad del artículo 259 de la LGS es la de facilitar el proceso de aumento de capital, excluyendo el DSP y haciendo el proceso mucho mas sencillo, y sobretodo, rápido; $y$,

2) La justificación a la exclusión del DSP se da justamente en el caso de las sociedades anónimas abiertas, en donde el accionariado difundido que pueden llegar a tener hace complicada e ineficiente la tarea de hacer que todos los accionistas renuncien a su DSP, sobre todo en aquellos casos en los que se requiere que todos los accionistas renuncien a este derecho porque el aporte se efectuará por terceras personas.

\section{REQUISITOS DEL ARTÍCULO 259 DE LA LGS}

Habiendo visto cuál es la justificación y finalidad del referido artículo 259 de la LGS, debemos entrar a analizar cuáles son los requisitos de su aplicación. Como hemos podido apreciar, la exclusión del DSP es algo necesario en aquellas sociedades anónimas abiertas con un accionariado difundido; sin embargo, esto no cambia el hecho que esta exclusión no debe de ser tomada a la ligera bajo ningún supuesto. A esos efectos, se deberán tener en cuenta los siguientes requisitos:

a) Se deberá tratar de una sociedad anónima abierta: •

13 ELÍAS LAROZA, Enrique, Derecho Societario Peruano, La Ley General de Sociedades, Fascículo Quinto, Edición 2001, Editora Normas Legales S.A.C., Trujillo, 1998, pp. 521-522.

14 SALAS SÁNCHEZ, Julio, Op. Cit., p. 20. 
El primer requisito a tener en cuenta y es uno que ya hemos venido reiterando es que el aumento de capital con exclusión del DSP se debe efectuar única y exclusivamente en las sociedades anónimas abiertas.

En este sentido, de acuerdo a lo indicado, la finalidad del artículo 259 de la LGS no tendria sentido en una sociedad anónima cerrada, por ejemplo. Esto, dado que la cantidad máxima de accionistas que una sociedad anónima cerrada puede tener, conforme a ley, es 20, por lo que carecería de lógica que un artículo diseñado para sociedades con un accionariado difundido sea aplicado en sociedades cuyo número de accionistas es considerablemente menor.

b) ¿El aumento de capital deberá ser por nuevos aportes?:

Como sabemos, los aumentos de capital en las distintas sociedades reguladas por la LGS pueden ser efectuados bajo distintas modalidades. Aunque todos impliquen de alguna u otra manera aumentar la cifra de la cuenta "capital" en el balance, la manera cómo se logra este cometido puede ser variado. Así por ejemplo, de conformidad con lo establecido en el artículo 202 de la LGS, los aumentos de capital pueden originarse en:

- Aumento de capital por nuevos aportes;

- Aumento de capital por capitalización de créditos contra la sociedad, incluyendo la conversión de obligaciones en acciones;

- Aumento de capital por capitalización de utilidades, reservas, beneficios, primas de capital o excedentes de revaluación; y,

- Aumento de capital por los demás casos previstos en la ley (por ejemplo, cuando una sociedad recibe un bloque patrimonial con valor positivo)
Asi pues, tenemos que:

"(...) desde el punto de vista patrimonial el aumento puede ser absoluto o contable. EI primero implica un incremento del patrimonio mediante la aportación de nuevos elementos, mientras que en el segundo no hay tal ingreso sino un traslado de partidas en el balance social, pasando a figurar como capital y cumpliendo su función elementos del patrimonio que antes eran ajenos a él. Este último caso puede producirse mediante la transformación de reservas o beneficios, la compensación de créditos o la conversión de obligaciones en acciones". ${ }^{15}$

No obstante haber diversas razones y modalidades para poder aumentar el capital, el artículo 259 es tajante al señalar que la aplicación del mismo ocurre "En el aumento de capital por nuevos aportes (...)", frase que, aparentemente, excluiría la posibilidad de aplicar el artículo 259 cuando se decida efectuar, por ejemplo, un aumento de capital por capitalización de créditos.

Asimismo, el texto del artículo 259 de la LGS replica el texto del citado artículo 207, en el sentido que ahí también se establece que el DSP se aplica "En el aumento de capital por nuevos aportes"y además, que "No existe DSP en el aumento de capital por conversión de obligaciones en acciones (...)"; ambas frases excluirían -aparentemente- que el DSP se aplique en la capitalización de créditos.

Sin embargo, cabría hacer aquí una explicación aclarando este tema y es que muchas veces causa confusión respecto a si el DSP es aplicable para la capitalización de créditos o no.

Para empezar, debemos decir que el aumento de capital por capitalización de créditos se encuentra estipulado en el artículo 214 de la $\mathrm{LGS}^{16}$, pero, contrariamente a lo que a veces

15 Autores varios. Dirigido y presentado por GARRIDO DE PALMA, Víctor Manuel, Estudio Sobre las Sociedades Anónimas, Tomo ll, Editorial Civitas, Madrid, 1993, p. 317.

16 Artículo 214.- Aumento de capital por capitalización de créditos: 
se piensa, dicho artículo no contiene una sino dos modalidades de capitalización:

- La capitalización de créditos (ordinaria por decirlo así); $y$,

- La conversión de obligaciones en acciones

¿Cuál es la diferencia entre ambas? Como nos explica Torres Carrasco ${ }^{17}$, la capitalización de créditos distingue dos modalidades, primero la capitalización de créditos y segundo, la conversión de obligaciones en acciones. Aunque ambas tengan finalmente el mismo resultado (convertir a un acreedor en accionista) difieren en su oportunidad. De un lado, tenemos que la decisión de efectuar una capitalización de créditos ocurre durante la vida de dicho crédito, no habiéndose previsto este acto en el momento originario de su nacimiento.

Caso contrario, en la conversión de obligaciones en acciones, dicha conversión (es decir capitalización) ya se encontraba prevista o determinada (al menos como posibilidad) al momento del nacimiento de dicha obligación; esto es lo que se conoce como una "obligación convertible".
En este sentido, la posibilidad de llevar una determinada obligación a la cuenta del balance denominada "capital" se puede preveer desde un principio o se podría presentar durante el transcurso de vida de dicho crédito. En este orden de ideas, el momento de decisión hará la diferencia entre el primer y segundo párrafo del artículo 214 de la LGS.

Pues bien, una vez delimitado ambos tipos de capitalización, debemos señalar que la excepción contenida en el tercer párrafo del artículo 207 de las LGS, incluye únicamente la modalidad de capitalización descrita como conversión de obligaciones en acciones ${ }^{18}$, siendo plenamente factible que se aplique para la capitalización de créditos ordinaria. Como bien señala Elías Laroza ${ }^{19}$ :

“Concluye el artículo 207 señalando los casos en que no es exigible el DSP:

En el aumento de capital por conversión de obligaciones en acciones. Ello se debe a que los accionistas tuvieron la facultad de ejercer el derecho oportunamente, al momento de la emisión de las obligaciones convertibles, de conformidad con el artículo 316".

"Cuando el aumento de capital se realice mediante la capitalización de créditos contra la sociedad se deberá contar con un informe del directorio que sustente la conveniencia de recibir tales aportes. Es de aplicación a este caso lo dispuesto en el segundo párrafo del articulo anterior.

Cuando el aumento de capital se realice por conversión de obligaciones en acciones y ella haya sido prevista se aplican los términos de la emisión. Si la conversión no ha sido prevista el aumento de capital se efectúa en los términos y condiciones convenidos con los obligacionistas".

17 TORRES CARRASCO, Alberto, Validez y Oponibilidad del aumento de capital. En: Actualidad Jurídica, Tomo 90, 2001, Editorial Gaceta Jurídica, pp. 92-93.

18 Sobre lo dicho, nos permitimos aclarar un punto: Respecto a la posibilidad de ejercer el DSP en la conversión de obligaciones en acciones (las denominadas "obligaciones convertibles") siempre causa confusión el artículo 316 de la LGS, citado por Elías al momento de explicar la excepción del artículo 207 de la LGS. Al respecto, debemos definir que las obligaciones convertibles son aquellas que la sociedad emite (es decir, un documento conteniendo dicha obligación) y que contienen la posibilidad de convertirse, en algún momento determinado o determinable, en acciones propiamente dichas. Pues bien, conforme lo establece los artículos 304 y siguientes de la LGS, las obligaciones convertibles son emitidas como cualquier otra obligación y es en este primer momento en el que los accionistas tienen -conforme lo reconoce el propio articulo 316 de la LGS- derecho para suscribir dichas obligaciones convertibles; vale decir, pagar el importe de la acreencia y convertirse en acreedores y, posteriormente, accionistas. Sin embargo, mucha gente confunde la interpretación de este artículo, llegando a pensar que dicho artículo facultà a los accionistas de la sociedad a suscribir preferentemente las acciones que se emitan como consecuencia de la conversión. Esta idea es falsa ya que el derecho de suscribir preferentemente, otorgado a los accionistas en virtud del referido artículo 316 de la LGS, se debe ejercer única y exclusivamente al momento de la emisión de dichos titulo, más no asi en el momento de la conversión (valga la aclaración en acciones). En este orden de ideas, sí existe derecho para suscribir las obligaciones convertibles en acciones, pero no existe aquel derecho para suscribir las acciones que resultan de la conversión de obligaciones porque éstas últimas ya tienen un titular natural: el obligacionista.

19 ELIAS LAROZA, Enrique, Op. Cit., Fascículo Cuarto, p. 412. 
Entonces, teniendo en cuenta que el DSP es aplicable para la capitalización ordinaria de créditos, debemos plantearnos la siguiente interrogante: ¿está la exclusión del DSP en los casos de capitalización ordinaria de créditos permitida por el artículo 259 de la LGS?

Efectuando una interpretación literal del artículo objeto de análisis, podríamos llegar a la conclusión que la respuesta a la interrogantes es negativa; sin embargo, tomando como presupuesto el análisis efectuado en el 4. supra, consideramos que la finalidad del artículo 259 no puede verse limitada únicamente a aquellos supuestos de aportes nuevos, sino que debería ampliarse también a aquellos aumentos de capital por capitalización de créditos e inclusive, a cualquier otro supuesto que involucre una emisión de acciones nuevas, salvo por supuesto, la conversión de obligaciones en acciones. ${ }^{20}$

Afirmar que el artículo 259 no sería aplicable a estos supuestos sería desvirtuar la utilidad y finalidad del mismo, que como ya hemos visto es agilizar y simplificar los aumentos de capital en sociedades anónimas abiertas. Por último, siguiendo la misma lógica, la palabra "aportes" deberá ser entendida tanto como aportes dinerarios y no dinerarios, interpretando sistemáticamente el artículo 213 con el artículo 259 de la LGS y también, haciendo una interpretación ontológica del artículo 259 bajo análisis.

c) El acuerdo se deberá adoptar en Junta General de accionistas con el quórum del artículo 257 pero con el voto de no menos del $40 \%$ de las acciones suscritas con derecho a voto:

Un punto a tener en cuenta es que el acuerdo para excluir el DSP en un aumento de capital determinado debe guardar ciertas formas. Al respecto, se debe de tener algo en cuenta y es que a pesar de que ya existe el artículo 257 de la LGS (el cual es automáticamente aplicable a los casos de aumento de capital), era necesario especificar el tema de las mayorías, dado que el acuerdo de aumento de capital -a nuestro entender-, es totalmente distinto a adoptar el acuerdo de excluir el DSP. Uno es el acto y el segundo, la forma a través de la cual se realizará dicho acto.

Sobre lo dicho, debemos entender que la decisión de efectuar un aumento de capital no comprende necesariamente el acuerdo de efectuarlo sin el DSP; sin embargo, este último sí conlleva necesariamente la idea de efectuar un aumento de capital. Es así como la LGS hace una distinción entre el adoptar el acuerdo de aumentar el capital y adoptar un acuerdo en el sentido de determinar que dicho aumento de capital se llevará a cabo prescindiendo del DSP. Uno no debería confundirse con el otro.

En este orden de ideas, existe una diferencia entre la mayoría a adoptar para cada acuerdo. Debemos recordar que para el caso de decidir hacer el aumento de capital sin el DSP se requiere el voto favorable de por lo menos un $40 \%$ de las acciones suscritas con derecho a voto. Por otro lado, para el caso de decidir efectuar un aumento de capital -en el caso de sociedades anónimas abiertas-, se podría incluso requerir de tan solo la mayoría absoluta de cualquier número de acciones (esto por ejemplo, en el caso de llegar a tercera convocatoria). ${ }^{21}$

Por esta razón, si se siguiera únicamente lo dispuesto por el artículo 257 de la LGS, llegaríamos a la conclusión que el acuerdo

20 Valga la obviedad, debemos puntualizar que si el aumento de capital genera el incremento del valor de acciones ya existentes, no será necesario excluir el DSP ya que este no podría ser ejercido por los accionistas aún lo quisieran.

21 Recordando lo que dice el artículo 257 de la LGS: Artículo 257.- Quórum y mayoria:

"En la sociedad anónima abierta para que la junta general adopte válidamente acuerdos relacionados con los asuntos mencionados en el articulo 126 es necesario cuando menos la concurrencia, en primera convocatoria, del cincuenta por ciento de las acciones suscritas con derecho a voto. 
de prescindir del DSP se puede adoptar por prácticamente cualquier número de acciones; situación que entendemos, no busca el artículo 259 bajo análisis. ${ }^{22}$

d) Que la eliminación del DSP sea aplicable a todos y cada uno de los accionistas:

Este requisito se encuentra en perfecta coordinación con el siguiente punto y guarda concordancia con la idea de no variar la situación de solo algunos de los accionistas (beneficiando probablemente al resto). Como hemos venido diciendo, el DSP es un derecho básico y esencial a la calidad de accionista; $y$ aunque la eliminación de este para el caso específico de un aumento de capital sea válida, esto no implica que deba ser usado como elemento para causar un perjuicio.

Como es lógico, una de las formas más fáciles de causar perjuicio a algunos accionistas, utilizando el artículo 259, es hacer que la eliminación funcione para algunos y no para otros, logrando que los que mantienen el DSP puedan aumentar su porcentaje en el capital social de la compañía, en perjuicio de otros. Esto, como es lógico, no puede ser permitido.
En este orden de ideas, se debe de entender que el citado artículo 259 de la LGS tiene una finalidad práctica y busca simplificar asuntos que muchas veces complican la vida societaria de sociedades anónimas abiertas que cuentan con accionariado difundido. Esto, por supuesto, choca con la idea de utilizar este mecanismo como forma de agraviar intereses de accionistas de la compañía.

Se debe dejar en claro que aunque el texto del artículo 259 no lo diga de manera expresa, la. supresión del DSP debe operar para todos los accionistas de la sociedad, $\sin$ excepción alguna. ${ }^{23}$

Esto, como hemos dicho, es una de las formas a través de la cual se puede causar perjuicio a los accionistas de la sociedad. Sin embargo, dado que no es la única ( $y$ como la realidad supera muchas veces la legislación), el propio texto del artículo 259 dispone como requisito, el siguiente.

e) Que no se mejore la posición accionaria de alguno de los accionistas, sea de manera directa o indirecta:

En segunda convocatoria basta la concurrencia de al menos el veinticinco por ciento de las acciones suscritas con derecho a voto.

En caso no se logre este quórum en segunda convocatoria, la junta general se realiza en tercera convocatoria, bastando la concurrencia de cualquier número de acciones suscritas con derecho a voto.

Salvo cuando conforme a lo dispuesto en el artículo siguiente se publique en un solo aviso dos o más convocatorias, la junta general en segunda convocatoria debe celebrarse dentro de los treinta días de la primera y la tercera convocatoria dentro de igual plazo de la segunda.

Los acuerdos se adoptan, en cualquier caso, por la mayoría absoluta de las acciones suscritas con derecho a voto representadas en la junta.

El estatuto no puede exigir quórum ni mayoría más altas".

22 En este sentido, si bien es cierto no se busca un unanimidad al momento de adoptar el acuerdo, tampoco se busca que el mismo sea adoptado por un número cualquiera de acciones, sino que el acuerdo sea adoptado por el número de acciones que represente, cuando menos, el $40 \%$ de las acciones suscritas con derecho a voto.

23 Nuestra interpretación viene dada por el principio que establece que todos los accionistas cuentan con un grupo determinado de derechos básicos e inherentes y que estos no pueden ser ignorados. En este orden de ideas, el principio de igualdad ante la ley que regiría para los accionistas no permitiria que se prive del DSP a algunos y no a otros. Esto, por supuesto, haría que por un acuerdo de junta general de accionistas se ponga en situación de desventaja a algunos accionistas frente a otros. Este comportamiento, creemos, es contrario al espíritu no solo del artículo 259 de la LGS sino de toda la LGS en general. Suscribimos la opinión compilada por Garrido de Palma, quien dice que "Otro de los principios configuradotes de la sociedad anónima sobre los que se asiente la posición de socio es el principio de "paridad de trato", que implica la prohibición de un trato desigual arbitrario y sin fundamento material (Ennecerus)" (Autores varios. Dirigido y presentado por GARRIDO DE PALMA, Victor Manuel, Op. Cit., Tomo l, pp. 39-40). 
Como último requisito, tenemos uno de los más importantes señalados por el artículo 259 de la LGS y al mismo tiempo-creemos- uno de lo más flojos. Nos referimos al requisito que establece que el acuerdo de prescindir del DSP no sea utilizado para "mejorar la posición accionaria de alguno de los accionistas".

Este requisito es sumamente importante y es el único que se ha mantenido inamovible desde su antecedente en el Decreto Legislativo 672, manteniendo asimismo, el espíritu de dicha disposición. Asimismo, comentando el referido Decreto Legislativo 672, Julio Salas ${ }^{24}$ es de la opinión que si se fuera a excluir el DSP, la finalidad de esta exclusión no debería bajo ningún supuesto generar una situación de beneficio para algunos y de perjuicio para otros.

Sin embargo, consideramos quie aunque la intención del artículo ha sido acertada al senalar que se prohibe la "mejora de posición accionaria" (de manera directa o indirecta), creemos que el propio texto se ha limitado al delimitar el "beneficio" a una mejora en la posición en el accionariado de la sociedad; situación que nos parece inadecuada y restringida. Es nuestro entender que lo que quiso el legislador es evitar que se utilice el citado artículo para crear un perjuicio (u obtener un beneficio), situación que no se encuentra abarcada en el texto elegido por el legislador. En este sentido, el tenor de dicho numeral debería ser entendido en el sentido de no infligir un perjuicio $u$ obtener un beneficio.

Creemos que no debería cerrarse a la posibilidad que el artículo 259 de la LGS pueda ser utilizado para otra finalidad que no sea necesariamente mejorar la posición accionaria de uno o algunos de los accionistas (esto es, incrementar su porcentaje accionario).

Creemos que la LGS ha circunscrito el beneficio únicamente al hecho de suscribir más acciones que el resto, situación que aunque podría ser la mayoría de los casos, creemos que no es la única. Asimismo, podría incluso no haber un beneficio obtenido sino tan solo un perjuicio hacia otros accionistas, situación que creemos también debería de considerarse como un ilegal uso del artículo 259 de la LGS.

Por último, sobre el tema del perjuicio y/o beneficio que se pueda generar $u$ obtener a través del artículo 259 de la LGS, debemos decir que aunque el texto del artículo no lo defina, consideramos que debe ser uno que pueda ser actual o potencial y, principalmente, debidamente comprobado o comprobable.

En este orden de ideas, consideramos que el legislador se quedó corto al redactar el inciso 2 del artículo 259, limitándose únicamente a replicar literalmente lo ya dispuesto en su momento por el Decreto Legislativo 672; no analizando otras posibilidades. Desde acá, opinamos que hubiese sido óptimo que el tenor del mencionado literal hubiese sido más amplioy desarrollado, evitando asípotenciales discusiones respecto a si hubo o no un perjuicio.

De lo dicho debemos concluir que:

- El texto literal del artículo 259 de la LGS circunscribe el perjuicio que se pueda ocasionar utilizando este artículo a una "mejora de la posición accionaria". Sin embargo, creemos que la idea del legislador ha sido la de evitar un perjuicio (u obtener un beneficio), más que evitar una desproporción accionaria entre los accionistas;

- Siguiendo en esta línea, creemos que el beneficio que se pueda causar utilizando el mencionado artículo debe ser considerado de la manera más amplia posible, sea que se mejore la posición accionaria o no. En este sentido, sería mejor analizar si es que hubo un beneficio, antes que tratar de encasillar dicho beneficio en alguna $u$ otra categoría; 
- Así pues, se debe de entender esta limitación inclusive cuando no haya un beneficio para el perjudicante, dado que el solo hecho de perjudicar o poner en situación de desventaja a alguno(s) accionista(s) es suficiente para que el artículo en cuestión no sea utilizado. Igual razonamiento se aplicaría en forma viceversa. La idea creemos, es evitar que se cause un perjuicio o se reciba un beneficio indebido; $y$,

- Por último, el beneficio y/o perjuicio debe de ser actual o potencial $y$, principalmente, debidamente comprobado o comprobable; no pudiendo ser utilizado este inciso so pretexto de impedir el desarrollo de la sociedad.

\section{Explicación en la Junta General de Accionistas para su uso}

Un punto importante a tener en cuenta es que el artículo 259 no requiere de ningún sustento o explicación para poder ser utilizado en algún caso específico. En este sentido, consignar en el acta respectiva los fundamentos que sustenten la decisión de utilizar el referido artículo no puede ser considerado de ninguna manera como un requisito obligatorio a efectos de la aplicación del mencionado artículo. Sin embargo, al igual que cualquier aumento de capital, este deberá estar debidamente fundamentado ya que, de lo contrario, podría utilizarse para -por ejemplolicuar accionistas.

Hay que recordar que el artículo 259 se encuentra dentro de la normativa específica para las sociedades anónimas abiertas, por lo que cualquier sociedad anónima abierta que cumpla con los requisitos señalados podrá utilizar este artículo. Esto, por supuesto, no implica de manera alguna que se esté utilizando el referido artículo de manera arbitraria e infundamentada.

Creemos, dentro de todo, que como todo aumento de capital, deberían de existir sustentos reales que generen esa decisión, aún cuando dichas razones no sean reveladaś de manera explícita en el texto del acta.

\section{El caso de la oferta pública}

El último párrafo del artículo 259 establece la siguiente excepción:

“Excepcionalmente, se podrá adoptar el acuerdo con un número de votos menor al indicado en el inciso 1) anterior, siempre que las acciones a crearse vayan a ser objeto de oferta públi$c a$.

Un punto importante a tener en cuenta es la excepción planteada por la última parte del artículo objeto de análisis y que permite la posibilidad de adoptar el acuerdo de excluir el DSP con un porcentaje menor al $40 \%$, siempre que las acciones a crearse vayan a ser objeto de oferta pública.

Ahondando más, debemos interpretar lo que significa "adoptar el acuerdo con un número de votos menor al indicado en el inciso 1)", ya que dicho artículo no pone un límite mínimo, por lo que bien podría interpretarse que el acuerdo de excluir el DSP puede ser adoptado con un número de votos equivalente al mínimo establecido en el artículo 257 de la LGS, aplicable a las sociedades anónimas abiertas.

Sobre lo dicho, nos encontramos de acuerdo con Elías ${ }^{25}$ cuando dice que:

"Alno especificar la norma bajo comentario el porcentaje del total de las acciones suscritas con derecho a voto que debe ser considerado como "mayoría menor", consideramos que es de aplicación el quinto párrafo del artículo 257 de la Ley General de Sociedades, o sea la mayoría absoluta de las acciones que se encuentran representadas en la junta respectiva".

Como sabemos, el artículo 257 de la LGS establece mayorías menores a las planteadas por el artículo 259 de la LGS (40\% de la totalidad de 
acciones suscritas con derecho a voto) llegando incluso a establecer en su tercer párrafo lo siguiente:

"En caso no se logre este quórum en segunda convocatoria, la junta general se realiza en tercera convocatoria, bastando la concurrencia de cualquier número de acciones suscritas con derecho a voto".

Dado que el último párrafo del artículo 259 no plantea ningún límite, debemos entender que al eliminarse el mandato de adoptar el acuerdo con un mínimo de $40 \%$ de votos de las acciones suscritas con derecho a voto, se deja abierta la posibilidad de adoptar el acuerdo de conformidad con las reglas comunes de quórum y mayorías para sociedades anónimas abiertas establecidas en el artículo 257 de la LGS.

Arribando a esta conclusión, se podría válidamente afirmar que el acuerdo de aumentar el capital sin DSP (y cuyas acciones vayan a ser objeto de una oferta pública) podría adoptarse, en tercera convocatoria, con un quórum equivalente a 1 acción y una mayoría igualmente equivalente a 1 acción. No obstante este análisis, cabría válidamente preguntarse si al afirmar esto se estaría violando el derecho de los accionistas que no estuvieron ahi para adoptar el acuerdo.

Respondiendo a este punto, empezaremos diciendo que el último párrafo del artículo 259 de la LGS es la expresión máxima de la finalidad de dicho enunciado legal, ¿por qué? Pues porque si la finalidad del artículo 259 de la LGS es facilitar los aumentos de capital y la captación de recursos para el desarrollo de sus actividades, este último párrafo baja el estándar de uno de sus requisitos a su minima expresión: el acuerdo puede ser adoptado por cualquier número de acciones.
La razón de ser de esto es que, como sabemos, la LGS es del año 1998, año en el que el mercado de valores peruano no era lo que es hoy en dia; por lo que a manera de incentivar el desarrollo de las sociedades anónimas abiertas con accionariado difundido, el legislador creyó conveniente estimular la apertura de las sociedades a los mercados de capitales, haciendo pues que esta incursión sea lo más rápida y sencilla posible. Esto por supuesto, generaría captación rápida de recursos por parte de las sociedades anónimas abiertas, lo que a su vez les permitiría realizar mayores inversiones y emprender negocios de mayor envergadura. ${ }^{26}$

En este orden de ideas, el último párrafo del artículo 259 de la LGS sigue la misma línea y espíritu del resto del texto normativo, párrafo que además, conlleva una finalidad acorde con la intención de fomento empresarial y comercial que guarda todo el texto de la LGS.

Finalmente y, por las razones expuestas, no creemos que el último párrafo del artículo 259 de la LGS sea desproporcionado o que lesione los intereses de aquellos accionistas que no fueron (o no pudieron) acudir a votar. La excepción a este artículo-creemos-tiene todo un trasfondo y razón de ser, por lo que nos encontramos en total acuerdo con el mismo.

\section{EL CASO ESPECIFICO DE LAS SOCIEDADES CON DISTINTAS CLASES DE ACCIONES}

Una vez analizado las razones, fundamentos y requisitos de aplicación del artículo 259 de la LGS, toca entrar a analizar un punto en concreto en torno al aumento de capital sin DSP; esto es, el caso específico de aquellas sociedades anónimas abiertas que tienen distintas clases de acciones.

Como sabemos, la LGS permite que una sociedad tenga más de un tipo de acciones ${ }^{27}$, pudien-

26 Como diría Elias, "Esta norma busca que la sociedad anónima abierta acceda con mayor frecuencia al mercado de valores por la vía de la oferta pública, mecanismo de financiamiento alternativo al sistema tradicional (...)" (Ibid., p. 522).

27 Enumerando brevemente, podemos encontrar los artículos 88,95 y 96 de la LGS. 
do válidamente crear acciones que tengan, por ejemplo, un derecho preferente en el caso de reparto de utilidades o que carecen del derecho a voto. Para efectos de este análisis, no nos pondremos en un supuesto específico de tipo de acción, dado que la gama de derechos y/o limitaciones que puedan tener estas son diversas. Sin embargo, a efectos de tener un punto de apoyo, tomaremos como ejemplo, hipotéticas acciones sin derecho a voto. No obstante esto, dejamos en claro que el análisis podría -dado el caso-ser aplicado a alguna clase de acción que contengan otros derechos y/o limitaciones.

Como sabemos, el artículo 259 permite, en principio, adoptar un acuerdo de aumento de capital sin observar el DSP; acuerdo que como hemos visto, permite suprimir -momentáneamente- un derecho básico e inherente a todo accionista. Sobre esta idea, algunos podrían preguntarse si un acuerdo que afecta un derecho tan importante para los accionistas puede ser válidamente acordado por un grupo (o clase) de accionistas y opuesto a todos los accionistas en general.

Al respecto, algunos podrían considerar que cuando existen diversas clases de acciones, entraría en aplicación lo dispuesto por el artículo 132 de la LGS, referido a las juntas especiales. Antes de entrar al artículo 132 de la LGS, debemos decir que uno de los puntos centrales de la interrogante planteada en este punto es determinar si se debe llevar a cabo una junta especial de accionistas como consecuencia de la potencial afectación a los derechos de los accionistas tenedores de acciones sin derecho a voto. En otras palabras, ¿es la aplicación del artículo 259 una afectación de derechos de los accionistas que carecen del derecho a voto?

Sobre lo dicho, debemos puntualizar que, a diferencia del acuerdo opuesto a accionistas que no acudieron a votar, este supuesto implica que el acuerdo es adoptado por tan solo un número determinado de accionistas (pertenecientes a una clase), afectando a la totalidad de accionistas, incluso a aquellos que así quisieran votar en contra no podrían, por carecer del derecho a voto.

\section{Las Juntas Especiales y las circunstancias que las generan}

Para empezar, debemos decir que las juntas especiales tienen como finalidad fungir como etapa o requisito previo a una decisión posterior por parte de la junta general de accionistas, cuando esta tenga como finalidad la aprobación de algún acuerdo que pueda generar alguna de las siguientes consecuencias:

a) Eliminar una clase determinada de acciones; $\mathrm{o}$,

b) Afectar o modificar los derechos particulares de cualquier clase de acciones.

Tal y como lo establece Enrique Elías al comentar este artículo, su lectura debe ser concatenada a la del artículo 88 de la LGS, que establece la posibilidad de crear diversas clases de acciones, siendo que efectivamente "el artículo 132 de la Ley es el complemento natural del artículo 88".28 En este sentido, el referido artículo 88 establece en su tercer párrafo que:

"La eliminación de cualquier clase de acciones y la modificación de los derechos u obligaciones de las acciones de cualquier clase se acuerda con los requisitos exigidos para la modificación del estatuto, sin perjuicio de requerirse la aprobación previa por junta especial de los titulares de acciones de la clase que se elimine o cuyos derechos u obligaciones se modifiquen".

Asimismo, el artículo 132 de la LGS establece que:

"Cuando existan diversas clases de acciones, los acuerdos de la junta general que afecten los derechos particulares de cualquiera de ellas deben ser aprobados en sesión separada por la junta especial de accionistas de la clase afectada.

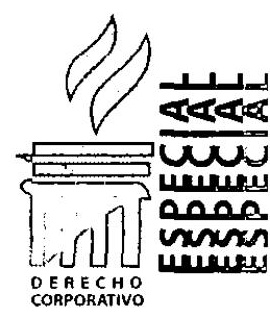

28 ELIAS LAROZA, Enrique, Op. Cit., p. 292. 
Lajunta especial se regirá por las disposiciones de la junta general, en tanto le sean aplicables, inclusive en cuanto al quórum y la mayoría calificada cuando se trate de los casos previstos en el artículo $126^{\prime \prime}$.

No obstante lo mencionado, es necesario recalcar que las juntas especiales no son de aplicación en cualquier supuesto, sino que serán necesarias únicamente en aquellos supuestos en los que se pretenda modificar (o eliminar) los derechos particulares de algún sector de accionistas. En este punto, debemos explicar que el enunciado del articulo hace mención a los derechos "particulares", los que deberían ser entendidos únicamente como aquellos derechos individuales o excepcionales atribuidos a clases especiales de acciones; a diferencia de los derechos atribuidos a la generalidad de accionistas.

En este sentido, consideramos que el espíritu del artículo es la de proteger a las distintas clases de acciones de las modificaciones o alteraciones que pudieran sufrir los derechos especiales que estas tengan; derechos distintos a los derechos "ordinarios" o "comunes", del resto de accionistas.

Partiendo de este punto de vista, la aplicación de las juntas especiales para los casos del artículo 259 sería totalmente inaplicable ya que el DSP, lejos de ser un derecho "particular" de alguna clase de acciones, es más bien general y aplicable a todas las clases de acciones.

No obstante esto, a efectos del presente análisis, partiremos del supuesto que la junta especial es necesaria cuando se afecte cualquier clase de derecho. Esta suposición se hace con el único fin de entrar a un análisis más profundo respecto a la aplicación del requisito contemplado en el artículo 132 de la LGS, dentro del marco del artículo 259 de la citada norma.

Entonces, retomando la idea, las juntas especiales son el modo de prevención que da la LGS para los accionistas de clases particulares de acciones. ¿Por qué? Porque se considera que estos accionistas podrían verse vulnerados con acuerdos adoptados por otra clase determinada de acciones (clase votante, por ejemplo) y no tener una forma o medio para defenderse contra dicho acuerdo.

Así pues, como bien lo señala Elías, crear una clase especial de acciones solo requiere de una modificación de estatutos pero eliminarla o modificar los derechos de éstas requieren necesariamente de la realización de una junta especial con dicho tipo o clase de acciones. ${ }^{29}$

\section{La afectación a los derechos de los accionistas sin derecho a voto como consecuencia de la supresión al DSP}

Hemos visto al inicio de este artículo cuáles son los fundamentos del artículo 259 de la LGS y cuál es la lógica que sigue al citado dispositivo legal. Ahora tocaría analizar si la supresión del DSP es, tal y como lo menciona el artículo 132 de la LGS, una afectación a los derechos particulares con los que cuentan estos accionistas.

Retomando lo ya expuesto líneas arriba, no podemos negar que el DSP es, en efecto, un derecho básico de cualquier accionista, derecho reconocido a lo largo de todo el cuerpo de la LGS. Sin embargo, el DSP, al igual que otros derechos (igualmente esenciales e inherentes), como lo son el derecho a voto, derecho a recibir un dividendo o derecho inclusive a transferir o gravar las acciones (vinculando inclusive a un derecho constitucional como to es el derecho de propiedad) puede ser limitado, eliminado o condicionado por decisión de la junta general de accionistas, disposición del estatuto o inclusive, por mandato directo de la ley.

Debemos entender que la LGS es una norma con carácter netamente práctico, que pocas veces se maneja en "absolutos" y que por encima de todo, privilegia el carácter comercial que rige la vida societaría, caracterizada básicamente

29 ELIAS LAROZA, Enrique, Op. Cit., Fasciculo Tercero, p. 281. 
por cualidades de rapidez, simplicidad y adaptabilidad. ${ }^{30}$

En este orden de ideas, creemos que la supresión del DSP es totalmente lícito y hasta necesario, tratándose de sociedades con accionariado difundido, por lo que, a pesar de que exista el artículo 132 de la LGS, debemos leerlo a la luz de lo expuesto por Elías, y sobre todo, de la excepción planteada en el artículo 259 de la LGS.

\section{1. ¿Requiere la aplicación del artículo 259 de la LGS de una junta especial previa?}

Asimismo, y continuando con esa línea de pensamiento, debemos decir que en el caso específico del DSP, no obstante se trata de un derecho mínimo, esencial y básico, la LGS debe leerse bajo una interpretación sistemática, vale decir, leyendo los artículos como complementos unos de otros, formando parte integrante de un todo ordenado y no como contradictorios o caóticos.

Debemos entender que la LGS, al igual que ocurre con otros cuerpos normativos es un texto que, en la medida de lo posible, intenta ser lo más coherente y ordenado posible. En efecto, se debe tratar de darle la interpretación más lógica y funcional que se le puede dar a un cuerpo normativo, intentando que todos los artículos coincidan entre si y se complementen, obviando interpretaciones restrictivas o sesgadas. ${ }^{31}$
En este sentido, uno debe entender y leer la referida normativa como complementos los unos de los otros. Si bien el artículo 207 de la LGS establece el derecho que tienen los accionistas de suscribir preferentemente las acciones emitidas en un aumento de capital, es el mismo articulo el que permite que dicho derecho sea excluido. En esta línea de ideas, el referido artículo 207 de la LGS menciona que:

"No existe DSP en el aumento de capital por conversión de obligaciones en acciones, en los casos de los articulos 103 y 259 ni en los casos de reorganización de sociedades establecidos en la presente ley". (El subrayado es nuestro).

En este sentido, aún cuando no se quisiera interpretar sistemáticamente los mencionados artículos, bastaría con tan solo efectuar una interpretación literal o estricta ${ }^{32}$ del artículo 207 de la LGS y entender que lo querido por el legislador ha sido obviamente permitir la eliminación del DSP en algunos supuestos, dejando entender claramente que si bien estamos ante un derecho básico, nos encontramos lejos de un derecho inamovible o absoluto. Esto, por supuesto, es igualmente aplicable a todos los accionistas, independiente del tipo o clase de acción que tengan.

Nosotros suscribimos plenamente la opinión de Enrique Elías ${ }^{33}$ cuando este efectúa sus

30 Nuevamente coincidiendo con Elías, debemos señalar que: "La segunda es haberse colocado en un punto de evolución diferente al del derecho europeo continental (...) no con el deseo de procurar originalidad a través de cambios, sino con el objetivo de buscar conscientemente una normativa mejor adaptada a las necesidades de las empresas peruanas en un mundo cada vez más dinámico, cambiante y de mercados globalizados.

Las distintas modalidades que podía adoptar la sociedad anónima, el crecimiento del mercado de valores, la globalización de la economia (...) entre otras tantas exigencias de los nuevos mercados, requerian de una legislación que fuese moderna, práctica y adecuada a las múltiples necesidades de las empresas y al mundo moderno" (ELIAS LAROZA, Enrique, Op. Cit., pp. iii-vii [Introducción]).

31 ESPINOZA ESPINOZA, Juan, Los Principios contenidos en el Título Preliminar del Código Civil Peruano de 1984, Segunda Edición, mayo de 2005, Pontifica Universidad Católica del Perú, Lima, 2005, pp. 213-214.

32 La interpretación estricta o literal es entendida como aquella en donde se lee exactamente lo que esta en el enunciado legislativo, sin que el interprete le de más, menos u otro significado distinto de aquél que literalmente se expresa en él. En efecto, se entiende que este tipo de interpretación existe "cuando el intérprete no añade ni quita, no aumenta ni disminuye los márgenes de aplicación de la norma". RUBIO CORREA, Marcial, Título Preliminar. En: Para Leer el Código Civil, Fondo Editorial de la Universidad Católica del Perú, 1986, p. 82.

33 ELIAS LAROZA, Enrique, Op. Cit., pp. 431 y 432. 
comentarios al referido artículo 207 de la LGS. Por último y para cerrar la idea, el solo enunciado que sea posible y lícito la exclusión del DSP hace que esto no sea pues una afectación a ningún tipo de derecho y en consecuencia, que no sea necesaria la realización de una junta especial.

Por otro lado, habría que prestar atención a lo establecido por el artículo 259 de la LGS cuando habla de la toma del acuerdo. Al igual que otros artículos donde se habla acerca de adoptar acuerdos, el artículo 259 de la LGS precisa que - por razones obvias-el acuerdo se adopta con las "acciones suscritas con derecho a voto". Aunque parezca algo elemental, la propia redacción del citado artículo dejaría entender que no interesan cuántos tipos (o clases) de acciones existan, porque el acuerdo es adoptado únicamente por aquellos accionistas tenedores de acciones con derecho a voto.

Esto da por sentado el hecho que podrian existir acciones sin derecho a voto, las que igual se verían obligadas por el acuerdo de aquellas acciones que sí cuentan con derecho a voto, por ser-valga la obviedad- las únicas que pueden votar. Esto, por mas simple que parezca, podría generar problemas en aquellas sociedades que cuentan con acciones de distinta clase.

Todo esto arroja una sola conclusión y es que la aplicación del artículo 259 de la LGS no afecta de manera alguna ningún derecho de ninguna clase de acciones; siempre que dicho enunciado se aplique con los requisitos y parámetros señalados en su texto. Así pues, aún considerado que el DSP es un derecho "particular" (cosa que negamos), esto no sería una afectación digna de generar una junta especial ya que, lejos de ser un acto arbitrario o unilateral, se trata de una limitación totalmente válida y amparada por la ley, por lo que no generaría el requisito contemplado en el artículo 132 de la LGS.

\section{CONCLUSIONES}

Finalmente, luego de haber efectuado un análisis de los temas más relevantes contemplado en el artículo 259 de la LGS, podemos sintetizar todo lo visto en lo siguiente:

a) EIDSP es un derecho básico, mínimo y esencial a todos los accionistas, el cual cumple la finalidad de protección contra ciertas desigualdades o perjuicios que se puedan causar como consecuencia de un aumento de capital;

b) No obstante lo anterior, el artículo 259 de la LGS permite la exclusión del DSP, exclusión que responde a necesidades de practicidad en las sociedades anónimas abiertas;

c) Para la aplicación del artículo 259 de la LGS se requiere cumplir con ciertos requisitos y respetar ciertos parámetros; requisitos y parámetros sin los cuales la aplicación del artículo 259 de la LGS podría ser ilegal;

d) Como parte de estos parámetros, consideramos que la aplicación del artículo bajo análisis se puede dar para aquellos aumentos de capital que, a excepción de la conversión de obligaciones en acciones, impliquen un aumento de capital y una emisión de nuevas acciones. Asimismo, lo que se entienda por "perjuicio" o "beneficio" al momento de utilizar el referido artículo debería ser interpretado de la manera más amplia posible. Sin embargo, dicha limitación no debería de ser utilizada so pretexto de truncar el desarrollo de la sociedad;

e) Respecto a aquellas sociedades anónimas que cuenten con distintas clases de acciones, debemos concluir que la aplicación del artículo 259 de la LGS no genera el requisito de realizar una junta especial previa, dado que de ninguna manera la eliminación del DSP a la luz del citado artículo implicaría la afectación de los derechos particulares $-y$ para esto, tampoco los generales-de dichos accionistas. Por último, el acuerdo de suprimir el DSP es totalmente lícito, pudiendo ser opuesto a todos los accionistas, sin importar el tipo o clase de acción que tengan. 